\title{
The Relationship between Work Hazards and Quality of Nurses' Work Life in Operating Room at Menoufia University Hospital
}

\author{
Esraa G.Abd Elmawla ${ }^{1}$, Manal M. Ibrahim² and Gehan M. Diab ${ }^{3}$ \\ ${ }^{1}$ B.Sc. Nursing Science, ${ }^{2}$ Professor of Nursing Administration, and ${ }^{3}$ Assistant Professor of Nursing \\ Administration, Faculty of Nursing-Menoufia University
}

\begin{abstract}
Nurses should work at safe environment to maintain high work life quality and good patient care delivery. The purpose of the study: Is to determine the relationship between work hazards and quality of nurses' work life. Methods: A descriptive correlational design was used; the study was conducted in operating rooms at Menoufia university hospitals. A convenient sample of 92 nurses was recruited from operating nurses. Data was collected using three Instruments (two structured questionnaires and one observation checklist) adapted by the investigator. The first structured questionnaire was work hazards questionnaire. The second structured questionnaire was quality of work life questionnaire. The third Instrument was observation checklist to assess OR environment safety and nurses' compliance to safety measures. Results: Majority of the studied subjects exposed to high work hazards and low work life quality. Conclusion: There is a very highly statistically significant negative correlation between work hazards and quality of work life. Recommendations: Maintain safe work environment at operation rooms to increase quality of nurses' work life.
\end{abstract}

Key words: operating rooms, quality of work life, work hazards.

\section{Introduction}

Work is considered a basic of one's life experience. Every type of work brings with it risks and health hazards where the nature of work environment of nurses is a potential source of many types of hazards which might consequently lead to health problems (American Association of Occupational Health Nurses, 2012). Hazard can be defined as the exposure to a variety of substances that cause grave and mortal diseases over long period of time (Young, 2010). Health care providers could be liable to acquired infections from occupational exposure. Nurses are being the most vulnerable health care workers (Almalki, 2012).

Moreover, ergonomic factors predispose nurses to low back pain. Also they are liable to workplace violence (Rezaee and Ghasemi, 2014). Training initiatives purposeed at improving their knowledge and perception of job hazards can decrease the burden of occupational disease among health care workers (Nkoko et al., 2014). Work can be dangerous to nurses' health. Prolonged contact of OR personnel to open surgical site, frequent manipulation of sharp instrument, and the presence of relatively large quantity of blood create a hazardous work environment and put nurses always at potential risk (American Association of Occupational Health Nurses, 2012). Quality of work life (QWL) is the degree to which members of a work organization are able to satisfy important personal needs through their experiences in the organization. More specifically, QWL mean employees perceptions of their physical and psychological wellbeing at work (Othman and Lieng, 2017).

Quality of Work Life also refers to all the organizational inputs that maintain employees' satisfaction and enhancing organizational effectiveness. For managers and administrators, the term denotes improvement in the psychological aspects of work to improve productivity. Unions and workers interpret it as more equitable sharing of profits, job security, healthy and congenial working conditions. Still others view it as improving social 


\section{The Relationship between Work Hazards and Quality of Nurses' Work Life in Operating Room at Menoufia University Hospital}

relationship at workplace through autonomous work groups (Walton, 2010).

In health care organizations quality of work life has been described as referring to the strengths and weakness in the total work environment and organizational features such as policies and procedures, leadership style, operations and general contextual factors of setting, all have a profound effect on how staff views the quality of work life (O'BrienPallas et al., 2014).

Focusing on improving quality of work life to increase the contentment and satisfaction of employees can result in various advantages for both employees and organization (Swamy and Rashmi, 2015). Improvement in work life quality of nurses is critically important to ensure quality patient care. Nurses need a positive and safe work environment to work effectively which lead to strengthen organizational commitment and improve quality of careers. Decrease work hazards leads to increase quality of nurses work life (Gurses et al., 2011)

Significance of the study

Internationally, it is estimated that about 2.9 billion workers are exposed to hazardous risks at their respective workplaces every day, 6,300 people die as a result of occupational accidents or workrelated diseases, which are more than 2.3 million deaths per year. Over 337 million accidents occur at work annuall .Nurses who work in operating rooms are more likely to be injured by exposure to medical gases than workers in other areas. Furthermore annual mortality rate of nurses from work hazards are 1,249 per 100,000 workers.

The investigator will assess the relationship between work hazards and quality of nurses' work life at operating rooms which provide organizations with important information about nurses, such as job satisfaction, general well-being, work-related stress and hazards, these include strengthening organizational commitment, improving quality of care and increasing the productivity of both the individual and the organization and minimize incidence of injuries by identify common hazards and their effect on quality of work life in operating rooms.

\section{Purpose of the study}

To determine the relationship between work hazards and quality of nurses work life at operating rooms.

\section{Research Questions}

- What are the work hazards at operating rooms as perceived by nurses?

- What is the quality of nurses' work life at operating rooms as perceived by nurses?

- What is the relationship between work hazards and quality of nurses work life at operating rooms?

\section{Methods}

\section{Study Design}

Descriptive correlational design was conducted.

\section{Study Sample:}

Convenient sample of (92 nurses) was used from operations nurses at Menoufia university hospitals.

\section{Study Setting:}

The study was conducted in operating rooms at Menoufia university hospitals as follows: Cardiothoracic surgery operations at specialized hospital, General surgery operations at emergency hospital, (Orthopedic, Urology, Otolaryngology and Ophthalmic) surgery operations at the main hospital.

\section{Instruments of data collection}

Three measuring instruments was used to conduct this study:

The first Instrument: Self-administered questionnaire. It was adapted from Jingke (2011) and El -Enein (2011). It purposed to determine work related hazards facing 


\section{The Relationship between Work Hazards and Quality of Nurses' Work Life in Operating Room at Menoufia University Hospital}

nurses in operation rooms and it is consisted of two parts as following:

Part 1: social characteristics structured questionnaire concerned with collection of data related to nurses' socio-demographic characteristics: it includes questions about age, gender, marital status, experience and educational level.

Part 2: Exposure to work hazards Likert scale, to assess subjects' exposure to different types of hazards. This part include 21 items related to

different types of work hazards in Operation rooms (OR), These items were listed under 6 groups: accidental hazards contained (3 items), physical hazards contained (3 items) chemical hazards contained (4 items), biological hazards contained (2 items), mechanical hazard contained (3 items) and psychosocial and organizational contained (6 items). Six points Likert scale type used for each statement as follows: never (0), Rarely (1),Sometimes (2), Often (3), Usually (4) , Always (5).

Reliability of the instrument $(a=0.96)$

Total Scoring system of work hazards:

- High exposure to work hazards $>66 \%$

- Moderate exposure to work hazards $33-66 \%$

- Low exposure to work hazards $<33 \%$

The second Instrument: Quality of work life Likert scale was adapted from the National Institute for Occupational Safety and Health (NIOSH, 2012), to assess nurses' quality of work life at operation rooms. The questionnaire consists of 35 closed - end questions categorized under six main categories as follows: psychological work environment (6 items), job characteristics (6 items), salaries and incentives (5 items), teamwork (6 items), supervisor leadership style (6 items) and participation in decision making (6 items). Five - points
Likert scale used for each statement as follows: Strongly disagree (1), Disagree (2), Neutral (3), Agree (4), strongly agree (5).

Reliability of the instrument $(a=0.97)$

Total scoring system of quality of work life:

- High quality of work life $>66 \%$

- Moderate quality of work life 33$66 \%$

- Low quality of work life $<33 \%$

The third Instrument: Observation checklist which divided into two parts:

Part one: environmental safety observation checklist. It was adapted from Burden and Quinn (2006). Observation checklist of environment safety and administrative data was divided into two groups: general and specific OR environment.

-General OR environment consisted of 33 items that come under nine main categories, accident reporting (2 items), accident investigation ( 3 items), fire safety (10 items), proper handling of materials (2 items), storage of materials (4 items), waste collection (2 items), Waste disposal (3 items), Safety occupational health (4 items) and OR policy (3 items). Specific OR environment consist of 33 items that come under six main categories as the following: availability and efficiency of supplies ( 7 items), personal protective equipment (3 items), environmental sanitation ( 7 items), traffic pattern control (3 items), electrical safety (1 items), equipment and machinery (6) and biological waste management (6 items).

Reliability of the instrument $(a=0.96)$

Scoring system: this part was scored by given one for present item and zero for absent.

Save OR environment $\geq 60 \%$, Un save OR environment $<60 \%$. 


\section{The Relationship between Work Hazards and Quality of Nurses' Work Life in \\ Operating Room at Menoufia University Hospital}

Part 2: Observation checklist for assessing OR staff nurses' compliance to safety measures: It is adapted from Burden and Quinn (2006).

This Instrument purposed to assess OR staff nurses' compliance to safety measures that minimize exposure to work hazards. It was composed of 31 items related to OR nurses' performance under two main categories includes the following: Scrub nurse (18 items), Circulating nurse (13 items).

Reliability of the instrument $(a=0.96)$

\section{Total Scoring system of work hazards:}

High exposure to work hazards $>66 \%$

Moderate exposure to work hazards 33$66 \%$

Low exposure to work hazards $<33 \%$

The second Instrument: Quality of work life Likert scale was adapted from the National Institute for Occupational Safety and Health (NIOSH, 2012), to assess nurses' quality of work life at operation rooms. The questionnaire consists of 35 closed - end questions categorized under six main categories as follows: psychological work environment (6 items), job characteristics (6 items), salaries and incentives (5 items), teamwork (6 items), supervisor leadership style (6 items) and participation in decision making (6 items). Five - points Likert scale used for each statement as follows: Strongly disagree (1), Disagree (2), Neutral (3), Agree (4), strongly agree (5).

\section{Reliability of the instrument $(\mathrm{a}=0.97)$}

Total scoring system of quality of work life:

- High quality of work life $>66 \%$

- Moderate quality of work life 33$66 \%$

- Low quality of work life $<33 \%$
The third Instrument: Observation checklist which divided into two parts:

Part one: environmental safety observation checklist. It was adapted from Burden and Quinn (2006). Observation checklist of environment safety and administrative data was divided into two groups: general and specific OR environment.

-General OR environment consisted of 33 items that come under nine main categories, accident reporting (2 items), accident investigation ( 3 items), fire safety (10 items), proper handling of materials (2 items), storage of materials (4 items), waste collection (2 items), Waste disposal (3 items), Safety occupational health (4 items) and OR policy (3 items). Specific OR environment consist of 33 items that come under six main categories as the following: availability and efficiency of supplies ( 7 items), personal protective equipment (3 items), environmental sanitation (7 items), traffic pattern control (3 items), electrical safety (1 items), equipment and machinery (6) and biological waste management (6 items).

Reliability of the instrument $(a=0.96)$

Scoring system: this part was scored by given one for present item and zero for absent.

Save OR environment $\geq 60 \%$, UN save OR environment $<60 \%$.

Part 2: Observation checklist for assessing OR staff nurses' compliance to safety measures: It is adapted from Burden and Quinn (2006).

This Instrument purposeed to assess OR staff nurses' compliance to safety measures that minimize exposure to work hazards. It was composed of 31 items related to OR nurses' performance under two main categories includes the following: Scrub nurse (18 items), Circulating nurse (13 items).

Reliability of the instrument $(a=0.96)$ 


\section{The Relationship between Work Hazards and Quality of Nurses' Work Life in Operating Room at Menoufia University Hospital}

Scoring system: this part was scored by given one mark for each a checked comply and zero for not comply during three times of observation of nurses' compliance to safety measures.

- Perform action two times at least (comply)

- Perform action one time only or don't perform it (not comply)

- The Instrument was scored by given one for present item and zero for absent.

- Comply $\geq 85 \%$, Not comply < $85 \%$

Validity and Reliability of instruments

Validity of the questionnaires were assessed by using content validity by five experts (two professors and three assistant professors) in administrative nursing department in order to check the relevancy, clarity, fluency, and simplicity of each component in the questionnaires

.Necessary modifications were done and unnecessary questions were deleted were done to reach the final valid version of the instruments from the experts' perspective.

\section{Pilot study:}

The pilot study was carried out on 10 nurses representing $10 \%$ of the total nurses from different operations in study setting. The purpose was to determine the applicability of the study; the clarity and feasibility of the study Instruments. The participants in the pilot study were included the main study sample because no modification were done.

\section{Ethical considerations:}

The study proposal was approved by ethical committee of the faculty of nursing, Menoufia University. All participants provided their written concerning their acceptance to participate in the study and were informed about the study purpose and their rights to refuse or withdraw from the study and anytime. Confidentiality of the obtained information was ascertained. The study maneuvers do not entail any harmful effects on participants.

\section{Procedure:}

Official letter was sent from the dean of faculty of nursing to the dean of menoufia university hospital to conduct this study. The investigator was simply explained the purpose of the study to the staff nurses who agree to participate in the study. Data was collected during work time in the presence of the investigator.

\section{Data Analysis:}

Data entry was done using SPSS (Version 20) Quantitative data were expressed as mean and standard deviation and qualitative data were expressed frequency and percentage.

Spearman`s test was used for to find correlation between study variables.

A statistically significant difference was considered if $\mathrm{p}<0.05$.

A very highly statistically significant difference was considered if $\mathrm{p}<0.001$.

\section{Results:}

Table (1):

This table shows that less than half of nurses had their age less than 25 years. As regarding to gender, the majority of sample was female. Regarding to experience less than half of the nurses $(44.6 \%)$ had less than five years of experience. Concerning to educational level, the highest percentage $(59.8 \%)$ were holding technical nursing Institute. According to gender about two thirds of sample $(69.6 \%)$ were females. Regarding to marital status, more than three quarters of the study sample (87\%) were married.

Table (2):

This table illustrates total Percentage distribution of nurses according to their exposure to work hazards. It shows that more than three quarters $(82.8 \%)$ of nurses exposed to high work hazards. However only (17.2\%) of them are exposed to moderate work hazards. And no one of them is exposed to low work hazards.

Table (3): 


\section{The Relationship between Work Hazards and Quality of Nurses' Work Life in \\ Operating Room at Menoufia University Hospital}

This table show percentage distribution of OR nurses' compliance to safety measures that minimize exposure to work hazards. It shows that $(55 \%)$ of nurses comply with safety measures and (45\%) of nurses not comply with safety measures.

\section{Table (4):}

This table illustrate total percentage distribution of OR environmental safety and administrative measures that minimize exposure to work hazards and found that all the environments of studied operations are safe $(100 \%)$.

Table (5):

This table illustrates total Percentage distribution of nurses according to their levels of work life quality. It shows that more than three quarter of nurses $(80 \%)$ perceived that they have a low quality of their work life. However only (14\%) of them have a moderate work life quality.
And only (6\%) of them have high quality of work life.

\section{Figure 1:}

This figure illustrates the ranking of work hazards as perceived by the studied nurses. It shows that the highest work hazards that face nurses are biological hazards $(100.0 \%)$, while the lowest work hazards are physical hazards $(52.4 \%)$.

\section{Figure 2:}

This figure illustrate ranking of quality of work life as perceived by the studied nurses. It shows that job characteristics are the highest dimension of quality of work life $(56.2 \%)$ while the lowest dimension is supervisor's leadership style $(33.3 \%)$.

Figure 3: This figure illustrates the relationship between work hazards and quality of work life. It shows that there is a negative correlation between work hazard

Table (1): Percentage distribution of socio- demographic characteristics of studied nurses $(n=92)$.

\begin{tabular}{|ll|c|c|}
\hline Variable & \multicolumn{2}{|c|}{ Frequency } & Percent \\
\hline Age (years) & $<25$ years & 41 & 44.6 \\
& $25-35$ years & 33 & 35.9 \\
& $>35$ years & 18 & 19.6 \\
\hline \multicolumn{2}{|c|}{ Mean \pm SD $29.0 \pm 5.4$ years } \\
\hline Gender & Male & 28 & 30.4 \\
& Female & 64 & 69.6 \\
\hline Experience & $<5$ years & 41 & 44.6 \\
& $5-10$ years & 25 & 27.2 \\
& $>10$ years & 26 & 28.2 \\
\hline Education & Nursing diploma & 6 & 6.5 \\
& Nursing technical institute & 55 & 59.8 \\
& Nursing Bachelor & 31 & 33.7 \\
\hline Marital status & Single & 10 & 10.9 \\
& Married & 80 & 87 \\
& Divorced & 2 & 2.1 \\
\hline
\end{tabular}




\section{The Relationship between Work Hazards and Quality of Nurses' Work Life in Operating Room at Menoufia University Hospital}

Table (2): Total Percentage distribution of nurses according to their exposure to work hazards $(n=92)$

\begin{tabular}{|l|c|c|}
\hline levels of work hazards & No & Percentage \% \\
\hline High work hazards & 76 & 82.8 \\
\hline Moderate work hazards & 16 & 17.2 \\
\hline
\end{tabular}

Table (3): Percentage distribution of OR nurses compliance to safety and measures that minimize exposure to work hazards $(n=92)$.

\begin{tabular}{|l|c|c|}
\hline Variables & No & \% \\
\hline Compliance to safety measures & 51 & 55 \\
\hline Not compliance to safety and measures & 41 & 45 \\
\hline
\end{tabular}

Table (4): percentage of OR environmental safety

\begin{tabular}{|l|c|}
\hline Variables & Percentage \% \\
\hline Safe OR environment & 100 \\
\hline Not Safe OR environment & 0.00 \\
\hline
\end{tabular}

Table (5): Total Percentage distribution of nurses according to their levels of work life quality $(\mathrm{n}=92)$.

\begin{tabular}{|l|c|c|}
\hline Classification of nurses Quality of work life. & No & Percentage\% \\
\hline High quality of work life & 6 & 6 \\
\hline Moderate quality of work life & 13 & 14 \\
\hline Low quality of work life & 73 & 80 \\
\hline
\end{tabular}

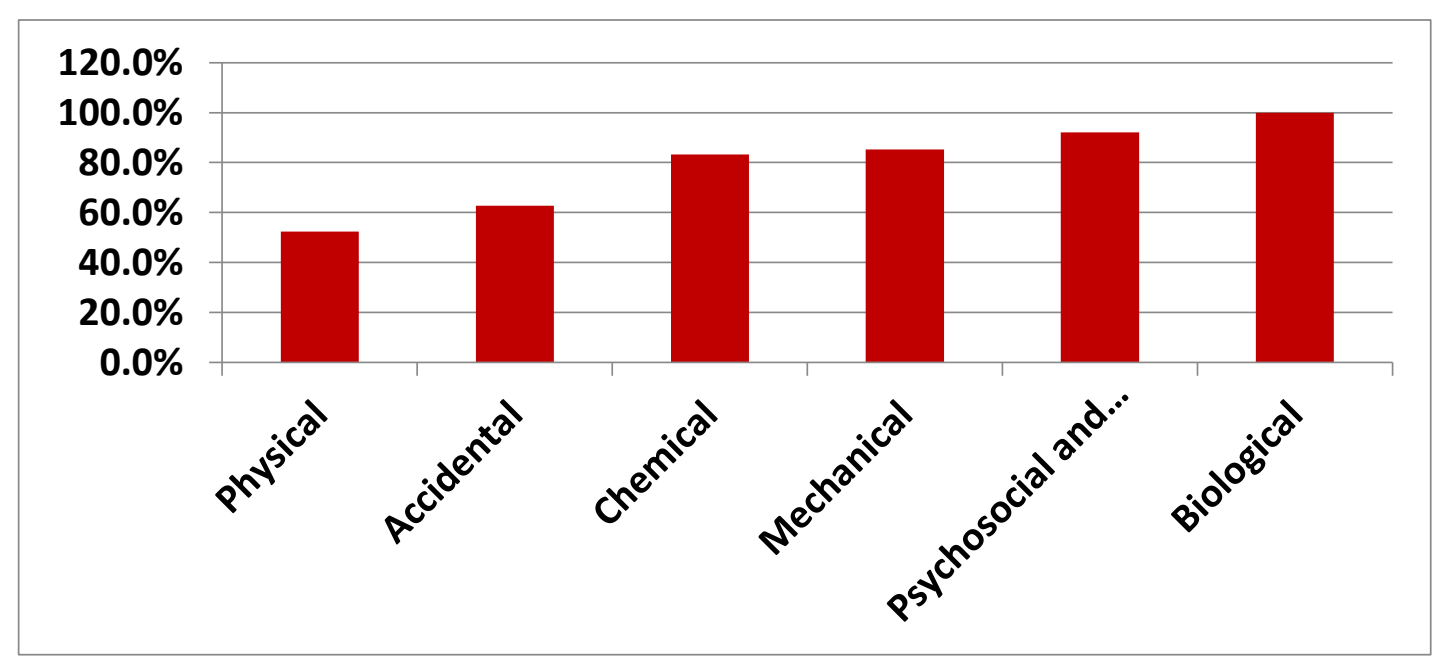

Figure1: Ranking of work hazards as perceived by the studied nurses $(n=92)$. 
The Relationship between Work Hazards and Quality of Nurses' Work Life in Operating Room at Menoufia University Hospital

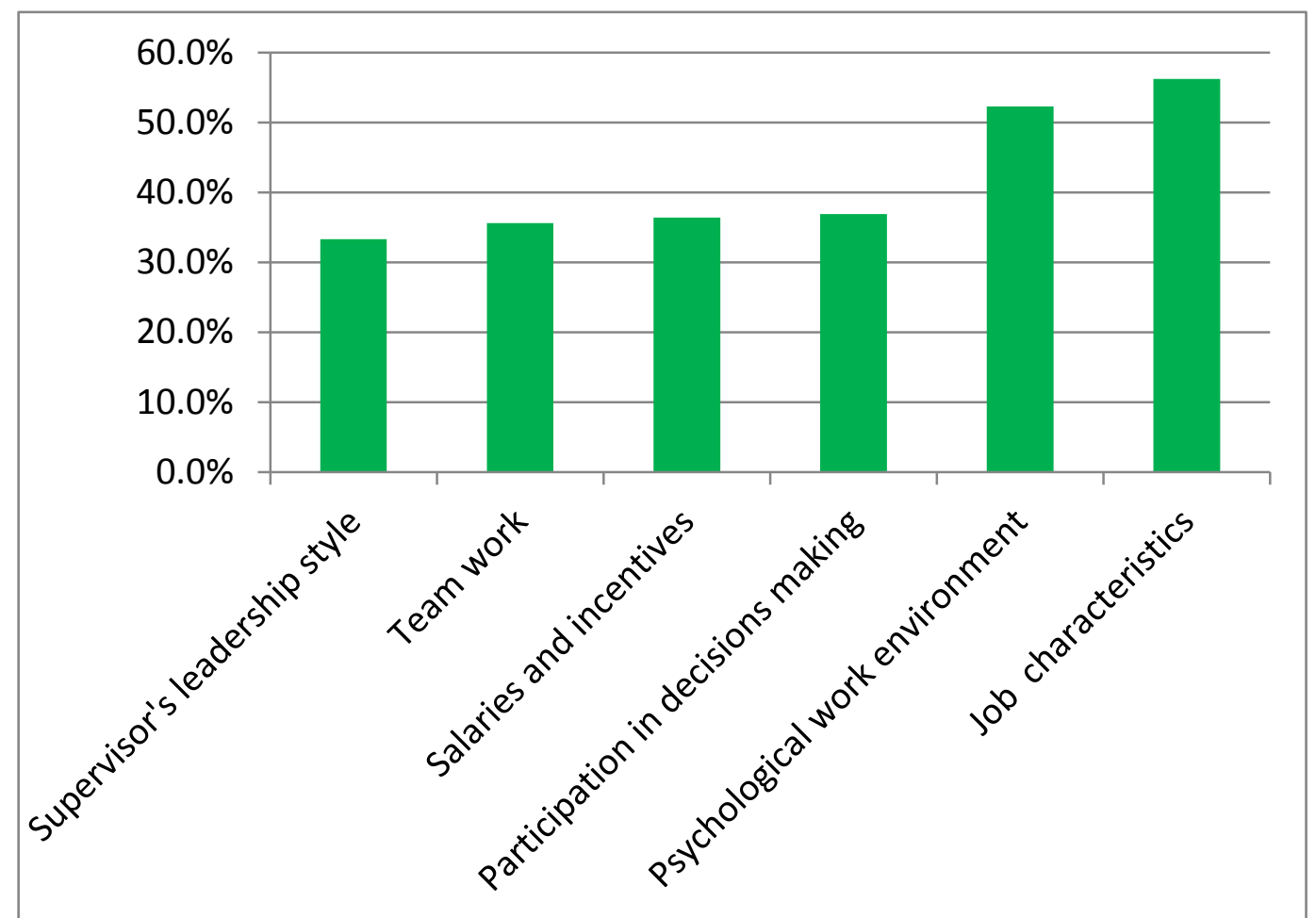

Figure 2: Ranking of quality of work life as perceived by the studied nurses $(n=92)$.

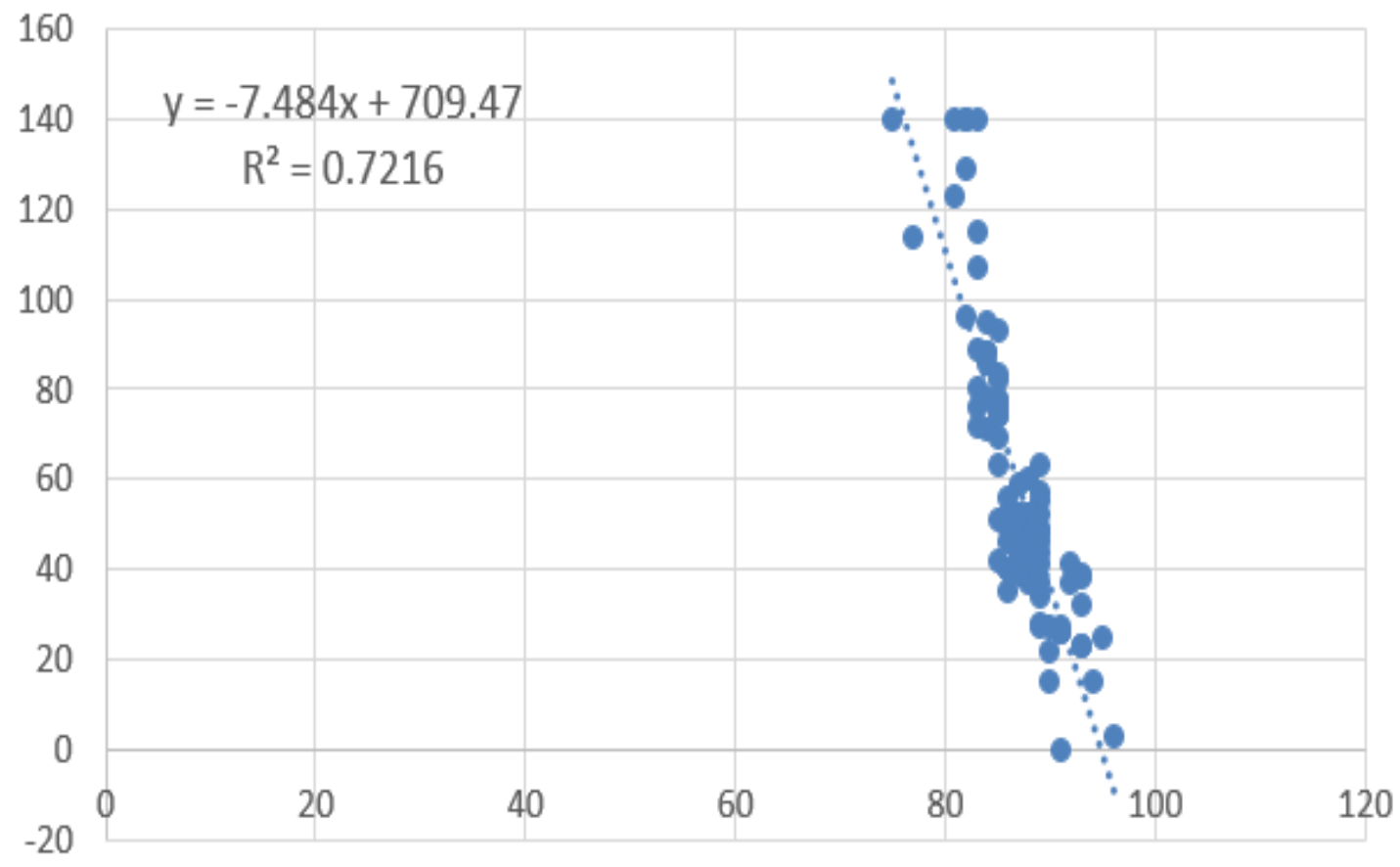

Figure 3: Relationship between work hazards \& Quality of work life (n=92). 


\section{The Relationship between Work Hazards and Quality of Nurses' Work Life in \\ Operating Room at Menoufia University Hospital}

\section{Discussion:}

Regarding to first variable of this study (work hazards). The study findings revealed that majority of studied nurses perceived that of nurses are exposed to high work hazards and the most commonly reported work hazards are biological, Psychosocial and organizational hazards. Regarding to first variable of this study (work hazards). Concerning nurse's exposure to different types of work hazards the result of the study revealed that the highest percentage of hazards was for biological hazards and the lowest exposure was to physical hazards.

The most frequent biological hazards are infected wounds, body fluids body tissues and mucous membranes. This finding is congruent with (Soule, 2018) who agreed that nurses are required to minimize risk of personnel exposure to body and body fluids. This high exposure may be due inadequate follow of the infection control rules and policies, and also to lack of continuing education after graduation, with the argument that they don't have time to read anything new, at a time when the technology and medical sciences are advancing very fast.

As regards nurses exposure to lowest work hazards (physical hazards), it was found that $\mathrm{x}$ - ray radiation and noise are the most common physical hazard observed in the work area and half of them are exposed to temperature. From the investigator perspective this could be due to deficits in the staff knowledge, lack in training about how protect themselves from exposure to physical hazards especially radiation hazards as reported in study findings. In addition the majority of nurses are highly exposed to radiation during operation due to lack of their knowledge.

These findings agreed with (Pittet, 2017) who identified that extreme temperature, vibration and radiation are the most common physical hazards in the workplace. Additionally, (Centers for Disease Control and Prevention, 2010) stressed that members of the health care teams are exposed to a list of potential hazards including radiation. Moreover, (National Institute for Occupational Safety and Health, 2015) reported that nurses are potentially exposed to radiation from $\mathrm{x}$ rays and radioactive isotopes. These risks can be due to incorrect work practices (working without self-protection).

The results of the current study reflect that more than three quarters of nurses are exposed to noise than other health care team which may lead to many problems. This is in agreement with (Centers for Disease Control and Prevention, 2010) which report that exposure to excessive noise level over a long period can cause hearing loss and an increase in blood pressure and stress levels.

Regarding studied nurses' compliance to safety measures we found that about this table show that only $55.0 \%$ of nurses are comply with safety measures. (Eqtait, 2015) agreed with study results that the majority of nurses did not carry out or perform certain procedures in relation to infection control precautions. Such as use of protective barriers gloves, mask, apron and correct disposal of needles and sharp instrument label. (Almurr , 2013) disagreed with study result mentioned that regarding compliance of nurses to personal protective equipment the result showed that quarter of them wear mask (Tuvadlmbwa, 2015) supported the study result revealed that, the majority of respondents indicated that occupational hazardous can be prevented by wearing, using protective measures.

As regards workplace safety, the investigator found that all studied operations environments are safe. From the investigator perspective this study results are due to availability of safety measures 


\section{The Relationship between Work Hazards and Quality of Nurses' Work Life in Operating Room at Menoufia University Hospital}

and supplies. ( Chung , 2020) agreed that operation rooms should be isolated physically from contaminated general environments, and maintain this isolation by, for example, not having any windows connecting to the outside. But this isolation can cause problems, such as communication difficulties between other work teams. However, these problems can be overcome with the use of modern communication technology.

Regarding the second variable investigated in the present study (quality of work life), results shows that the majority of them have low quality of work life. From the investigator perspective these findings are due to lack of nurses' satisfaction with quality of work life dimensions (working conditions, job characteristics, salaries and incentives, team work, supervisor's leadership style, and participation in decision making). This study finding agrees with (Kumar, 2016) who mentioned that, nurses in Isfahan hospitals had poor quality of work life. In the same line (Dargahi et al., 2012) reported that most nurses were not satisfied with all components of their quality of work life. Also (Morsy and Sabra, 2015) indicated that nurses were dissatisfied about their quality of work life.

In relation to staff nurse perception regarding first and highest dimension of quality of work life (job characteristics). From the investigator perspective this is due to feeling accountable of all what they do, job assignments and activities are important, and have skills necessary to perform their job. Therefore (Hajbaghery et al., 2012) who concluded that improving hospital subsystems, improving the distribution of activities among employee could improve quality of work life

Similarly, a study done by (kumar, 2016) investigated the relationship between the qualities of work life and work in acute care units. It concluded that most nurses in the acute care unite perceived job characteristics regarding quality of nursing work life high, which have an impact on their job. On the contrary (Abdallah, 2017) who concluded that job characteristics are second ranked in quality of work life.

Regarding the last dimension of quality of work life (supervisor leadership style) only $30 \%$ of nurses were satisfied with supervisor leadership style. From the investigator perspective this is due to no satisfaction with communication pattern between head nurses and nurses, low participation in solving problems, and lack of freedom of talking appropriate actions available to work. Also may be due to lack of justice and poor planning skills. Supervisors weren't encouraging staff nurses' share in decisions, explain job objectives clearly and competent in motivating employees.

Similarly, (Ahmed, 2011) clarified that, more than half of the staff nurses were moderately satisfied with their supervisors. Also (Chow, 2015) in Hong Kong who found that, the majority of the respondents had low agreement with authority of supervisor. In addition (Abd-El hamid, 2014) who reported that, subjects working at ICU at Nasser Institute Hospital were dissatisfied with supervision. This study finding is in contradiction with (Heidarie et al., 2012) who mentioned that studied nurses were satisfies with their supervisors' leadership style.

Regarding relationship between work hazards and quality of work life, we found that there was a negative correlation between work hazards and quality of work life. From the investigator perspective this could mean that good work life quality is associated with safe and hazard free work environment and the presence of hazards reduce quality of nurses work life. Study findings agreed with (Swamy and Rashmi, 2015) who revealed that decreasing work hazards lead to increased quality of work life. Also (Gurses et al., 2011) agreed that 


\section{The Relationship between Work Hazards and Quality of Nurses' Work Life in \\ Operating Room at Menoufia University Hospital}

maintenance of safe work environment lead to improvement at work life quality of nurses.

\section{Conclusion}

In the light of the present study results, it can be concluded that more than three quarters of nurses exposed to high level of work hazards and the rest of them exposed to moderate level of work hazards. Nurses reported that the first types of work hazards (biological hazards) were provided by the highest percentage. While physical hazards were provided by the lowest percentage. More than three quarter of nurses perceived a low quality of their work life. Additionally, there is a highly significant negative correlation between work hazards and quality of work life.

\section{Recommendations}

Disseminate the study results to the important key persons (hospital administrators) to decrease work hazards and increase quality of nurses' work life.

Provide all protective measures for nurses' safety.

Apply infection control policies to guide nurses' performance.

Involve nurses at making decisions related to their work to increase their work satisfaction.

Provide newly employed nurses with wellprepared orientation program about work hazards.

Provide nurse managers/supervisors with training programs on the art of management, leadership and communication skills to increase nurses' quality of work life.

Provide opportunities to attend nursing conferences and workshops to improve their knowledge about infection control and safety rules.
Further research is also needed to assess the impact of work hazards on quality of nurses work life.

\section{References}

[1] Abdullah, K. (2017). The relationship between job satisfaction and intention to leave current employment among registered nurses in a teaching hospital. Journal of Clinical Nursing ;( 22):3141-3152.

[2] Abd El Hamed, M. (2014). The Effects of Emotional Intelligence on Job Satisfaction, Journal of Information \& Knowledge Management; (6):98-110.

[3] Almalki, M. (2012). Quality of work life among primary health care nurses in the Jazan region, Saudi Arabia: A cross-sectional study; 10(1):30-36.

[4] American Association of Occupational Health Nurses (2012). Standards of occupational and environment health nursing. Atlanta (4) version, GA: AAOHN.

[5] Ahmad, N., Samia, M., Iman, A. (2011). Patient safety: assessing nurses' perception and developing an improvement plan. Life Sci J; 8 (2): 53-64.

[6] Almurr, B. (2013). Knowledge and Practice of Standard Precaution and Sharp Injures among Nurses in the Northern West Bank Hospitals; 3(6):100-120.

[7] Centers for Disease Control and Prevention (2018). Work-Life Imbalance and Musculoskeletal Disorders among South Korean Workers; 14(11):13-31.

[8] Chung, H. (2020).Operating Rooms of the future;1(3):53-64 .

[9] Eqtait, F. (2015).Knowledge and Practice of Nursing Staff towards Infection Control Measures in the Palestinian Hospitals ,Journal of Education and Practice ; 6(4):66-77.

[10] Gurses, A., Carayon, P., and Wall, M. (2011). Impact of performance obstacles on intensive care nurses' workload: perceived quality and safety 


\section{The Relationship between Work Hazards and Quality of Nurses' Work Life in \\ Operating Room at Menoufia University Hospital}

of care and quality of working life.

Health Services; (44): 422-445.

[11] Hajbaghery, M., Khamechian, M., and Alavi, N. (2012). Nurses' perception of occupational stress and its influencing factors: A qualitative study. Iranian Journal of Nursing and Midwifery Research, 01 Jul 2012, 17(5):352-359.

[12] Kumar, B. (2016). Effects of Age and Experience on Job Satisfaction and Organizational Commitment, Institute of Chartered Financial Analysts of India, University Journal of Organizational Behavior; (1):28-36.

[13] Jingke, G. (2011). An Investigation of the Impact of Operating Room Occupational Hazards on Intraoperative Nurses. JAMK University of Allied Sciences ;( 31): 22-25.

[14] Morsy M., and Sabra, E. (2015). Relation between quality of work life and nurses job satisfaction at Assiut University Hospital. Al Azhar Assiut Med; 13(3):163-171.

[15] National Institute of Occupational Safety and Health (2014).Integrating Worksite Health Protection and Health Promotion: A Conceptual Model for Intervention and Research; (91): 188196.

[16] Nayeri D., Salehi T., and Noghabi A. (2012).Quality of work life and productivity among Iranian nurses; 39(1):106-118.

[17] Nkoko L., Spiegel J., Rau A., Parent S., and Yassi A. (2014). .Reducing the risks to Healthcare workers from blood and body fluid exposure in a small rural hospital in Thabo Mofutsanyana, South Africa. Workplace Health Safety; (62):382388.

[18] O'Brien, L., Baumann, A., and Villeneuve, M. (2014). Research unit probes quality of work life; 6(1):14 16.

[19] Othman, A., and Lieng, M. (2017). Relationship between qualities of work life (QWL) and job satisfaction: a case study of enterprise "XYZ" in Malacca. International Conference on Human Capital Development, Pahang, 25-27.

[20] Pittet, R., (2017).Gender issues in safety and health at work; a review Book Publisher: European Agency for Safety and Health at Work; 92-104.

[21] Soule, O. (2018). The Challenge of Health Care Financing Reforms Vol. XIII No.

[22] Philippines, Philippine Institute for Development Studies https://dirp4.pids.gov.ph/ris/drn/pidsdr $\underline{\mathrm{n} 95-6}$

[23] Rezaee, M., and Ghasemi, S. (2014). Prevalence of Low Back Pain among Nurses: Predisposing Factors and Role of Work Place Violence.

[24] Swamy, R., Rashmi, S., and Nanjundeswaraswamy, T. (2015). Quality of Work Life: Scale Development and Validation, International Journal of Caring Sciences; 8(2):281-300.

[25] Tuvadlmbwa, M. (2015). HealthEducation Perceptions and Practices Related to Teaching HIV Prevention; 15(9):201-205.

[26] Walton, E. (2010). Criteria for Quality of Working Life. In L.E. Davis, A.B. Churns and Associates (Eds.); the Quality of Working. New York, the Free Press, Life, (1):91-104.

[27] Young, D., and Meyers, A. (2010). Chemicals exposure prevention for the patients and employee safety: nursing clinics of North America; 45(3):132149. 